\title{
Loss of p57 expression and RhoA overexpression are associated with poor survival of patients with hepatocellular carcinoma
}

\author{
TINGHUA HU ${ }^{1 *}$, HUI GUO $^{1 *}$, WENJUAN WANG ${ }^{1}$, SHUO YU $^{2}$, LILI HAN $^{1}$, LILI JIANG $^{1}$, \\ JIEQUN MA $^{1}$, CHENGCHENG YANG ${ }^{1}$, QIANQIAN GUO ${ }^{1}$ and KEJUN NAN ${ }^{1}$ \\ Departments of ${ }^{1}$ Oncology and ${ }^{2}$ Hepatobiliary and Pancreas Surgery, The First Affiliated Hospital, \\ College of Medicine, Xi'an Jiaotong University, Xi'an, Shaanxi 71006, P.R. China
}

Received April 25, 2013; Accepted June 27, 2013

DOI: $10.3892 /$ or.2013.2608

\begin{abstract}
Ras homology A (RhoA) have been implicated in the growth and metastasis of several types of human cancers. This study aimed to detect their expression in hepatocellular carcinoma (HCC) tissue specimens and to determine a possible association with clinicopathological data and patient survival. A total of $80 \mathrm{HCC}$ and corresponding distant normal tissue specimens were processed for immunohistochemical and qPCR analyses of p57 and RhoA expression. The data showed that expression of p57 mRNA and protein was reduced in HCC tissues when compared to that in distant non-cancer tissues $(\mathrm{P}<0.05)$, while expression of RhoA mRNA and protein was significantly higher in HCC tissue specimens when compared to that of the distant normal tissues. Loss of p57 expression was associated with HCC with higher $\alpha$-fetoprotein (AFP) levels (>400 ng/ml; P=0.044), larger tumor size ( $>5 \mathrm{~cm}, \mathrm{P}=0.004)$, poor tumor differentiation $(\mathrm{P}=0.020)$, advanced TNM stage $(\mathrm{P}=0.027)$, capsule invasion $(\mathrm{P}=0.018)$ and tumor thrombosis $(\mathrm{P}=0.008)$, whereas expression of RhoA protein was significantly associated with poor tumor differentiation $(\mathrm{P}=0.042)$, capsule invasion $(\mathrm{P}=0.022)$, and tumor thrombosis $(\mathrm{P}=0.002)$. Furthermore, there was a strong inverse relationship between $\mathrm{p} 57$ and RhoA expression in HCC tissues, indicating that loss of p57 expression may contribute to RhoA overexpression in HCC tissues. The median survival time of $\mathrm{HCC}$ patients with $\mathrm{p} 57^{+}$and $\mathrm{p} 57^{-}$expression was 13.0 and 9.0 months, respectively, whereas the median survival time of HCC patients with $\mathrm{RhoA}^{+}$and $\mathrm{RhoA}^{-}$was 9.0 and 15.0 months. Univariate analysis revealed that the levels
\end{abstract}

Correspondence to: Professor Kejun Nan, Department of Oncology, The First Affiliated Hospital, College of Medicine, Xi'an Jiaotong University, 277 Yanta West Road, Xi'an, Shaanxi 710061, P.R. China

E-mail: nankj@163.com

${ }^{*}$ Contributed equally

Key words: p57, Ras homology A, hepatocellular carcinoma, biomarker of AFP, tumor size, TNM stage, histological grade, capsule invasion, tumor thrombosis, p57, RhoA and co-expression of p57 and RhoA were all significant prognostic indicators for overall survival of HCC patients. Multivariate analysis showed that tumor size, TNM stage, p57, RhoA and combined loss of p57 with RhoA were risk factors for poor survival of $\mathrm{HCC}$ patients. This study indicates that the abnormal expression of p57 and RhoA contributes to progression of HCC and poor survival of patients.

\section{Introduction}

Hepatocellular carcinoma (HCC) is a significant health issue and is associated with poor prognosis and high mortality, accounting for more than 700,000 new cases and more than 600,000 cancer-related deaths each year worldwide. Half of these new cases and deaths are estimated to occur in China due to the epidemic prevalence of chronic hepatitis $\mathrm{B}$ virus infection. Other risk factors include hepatitis $\mathrm{C}$ virus infection, food contaminated with aflatoxin B1, alcohol-related cirrhosis, and nonalcoholic fatty liver disease (1). To date, there has been no significant breakthrough in the management of HCC; treatment options include surgery, liver transplantation, chemotherapy and targeted therapy. Most HCC patients are diagnosed at the late stage of the disease or have concomitant medical conditions, which account for the extremely poor survival rates (1). Thus, novel approaches or strategies to effectively control progression, detect the disease early, and predict prognosis are international priorities in HCC. Towards this end, our research focused on biomarker discovery and identification, and verification of novel biological markers for early detection or prediction of survival and treatment outcome.

p57 is a member of the Cip/Kip (CDK-interacting protein/kinase inhibition protein) family, a putative tumor-suppressor gene implicated in different types of human cancers, including HCC $(2,3)$. The gene p57 is maternally expressed and paternally imprinted, and encodes a 316-amino acid protein. It is located on chromosome 11p15.5, a region that has been associated with chromosomal abnormalities in multiple types of sporadic cancers and in familial Beckwith-Wiedemann syndrome (4,5). Loss of p57 expression frequently occurs in various types of human cancers, such 
as cancers of the thyroid, mammary glands, gastrointestinal tract, pancreas, prostate and bladder (6-9). Functionally, p57 has a key role in the timing of the cell cycle exit before cell differentiation. Previous studies have shown that p57 protein is a regulator of the G1/S transition of the cell cycle via cyclindependent kinases (CDKs) and ultimately affects proliferation and apoptosis of tumor cells $(10,11)$. In contrast, the knockout of p57 in mice resulted in much larger creatures, since p57 is a negative regulator of the cell cycle $(12,13)$.

p57 protein is also involved in the regulation of cell migration $(14,15)$. The metastasis of primary tumors is facilitated by the migration and invasion capabilities of tumor cells. This aggressive phenotype is regulated through cytoskeletal dynamics, and in particular involves the Rho family of GTPases (16). RhoA is a member of this family, and participates in regulating the actin cytoskeleton during cell locomotion and adhesion (17). During cell movement, RhoA contributes to the formation of actin stress fibers and the focal adhesion assembly, a key regulator of cell adhesion and motility in cancer cells $(18,19)$. Overexpression of RhoA has been observed in many types of malignancies, including noninflammatory breast, lung, pancreatic, colorectal and gastric cancers, and melanomas $(20,21)$.

Previous studies have shown that both p57 and RhoA proteins have inverse effects on the malignant behavior of cancers. What is more, the Cip/Kip family has been reported to control cytoskeletal organization and cell migration by regulating the Rho-ROCK-LIMK-cofilin signaling pathways $(14,22)$. It now appears that there may be direct crosstalk between cell-cycle proteins and the cytoskeletal regulatory proteins. Thus, in the present study, we performed immunohistochemistry and qRT-PCR to analyze the expression levels of p57 and RhoA in HCC tissue specimens and evaluate their association with clinicopathological parameters and survival of HCC patients.

\section{Materials and methods}

Patients and tissue samples. This study was approved by the Ethics Committee of Clinical Research of the First Affiliated Hospital, Medical College, Xi'an Jiaotong University. All patients provided written informed consent.

We obtained tissue specimens from $80 \mathrm{HCC}$ patients who underwent surgical resection of HCC lesions at the First Affiliated Hospital, College of Medicine, Xi'an Jiaotong University between December 2007 and December 2009. None of the patients had received prior radiotherapy or chemotherapy treatment. All patients were histologically confirmed with HCC by 3 independent and experienced pathologists. There were 56 men and 24 women patients, aged from 23 to 79 years (median age $45.62 \pm 10.89$ years) (Table I).

TNM stages were assigned to each patient according to the criteria of the 2002 Union for International Cancer Control. Tumor differentiation was assessed using Edmondson's classification. The 3-year follow-up for all of the patients was completed in December 2012. Cases lost to follow-up and those ending in death from causes other than $\mathrm{HCC}$ were regarded as censored data during the survival analysis.

Paraffin tissue blocks were retrospectively retrieved at the Pathology Department, which contained both cancerous and paired distant normal tissues (5 $\mathrm{cm}$ away from tumor lesions) for each patient. The tissue samples had been obtained in the operating room during surgery and were immediately snapfrozen in liquid nitrogen and stored at $-80^{\circ} \mathrm{C}$ for RNA isolation.

Real-time reverse transcriptase-polymerase chain reaction (qRT-PCR). Total mRNA was isolated from tissue samples using TRIzol reagent (Invitrogen Life Technologies, Carlsbad, CA, USA) and reverse-transcribed into cDNA using an RT-PCR kit (Takara, Dalian, China) in accordance with the manufacturer's instructions. Amplification of these cDNA samples was performed using SYBR Premix Ex Taq ${ }^{\mathrm{TM}}$ II (Takara) in accordance with the manufacturer's instructions in an iQ5 Multicolor real-time PCR detection system (Bio-Rad, Hercules, CA, USA).

The primers for $\mathrm{p} 57$, RhoA, and glyceraldehyde-3-phosphate dehydrogenase (GAPDH; internal control) were designed and synthesized by Takara. The primer sequences were: p57, 5'-GCGGCGATCAAGAAGCTGT-3' and 5'-ATCGCCCGAC GACTTCTCA-3'; RhoA, 5'-GACTCGGATTCGTTGCC TGA-3' and 5'-TGGGAACTGGTCCTTGCTGA-3; GAPDH, 5'-ACCACAGTCCATGCCATCAC-3' and 5'-TCCACCACCC TGTTGCTGTA-3'.

Each experiment was performed in duplicate and repeated 3 times. A dissociation curve analysis was conducted for each qPCR. Expression levels of the target gene were evaluated using a relative quantification approach $\left(2^{-\Delta \Delta \mathrm{Ct}}\right.$ method) against GAPDH levels.

Immunohistochemistry. To detect p57 and RhoA expression, we performed immunohistochemical staining. Briefly, after deparaffinization and re-hydration of tissue sections, the sections were first subjected to antigen retrieval in a pressure cooker in citric buffer for $10 \mathrm{~min}$. The sections were then incubated with $3 \% \mathrm{H}_{2} \mathrm{O}_{2}$ for $10 \mathrm{~min}$ at room temperature to block potential endogenous peroxidase activity and then incubated with $20 \%$ normal serum and further with a primary antibody against p57 (sc-56341, 1:200; Santa Cruz Biotechnology, Inc., Santa Cruz, CA, USA) or RhoA (10749-1-AP, 1:100; Proteintech Group, Chicago, IL, USA) at $4^{\circ} \mathrm{C}$ overnight. The negative control sections were incubated with phosphate buffered saline (PBS) only to replace the primary antibody. The next day the sections were washed thrice with PBS and then incubated with a biotinylated secondary antibody for $30 \mathrm{~min}$ at room temperature. Diaminobenzidine substrate was used to reveal immunoreactive products in the sections. After counterstaining with hematoxylin to reveal nuclei, the sections were mounted on slides and coverslipped.

To assess immunopositive cells, 3 pathologists reviewed the immunostained sections under a light microscope and scored the sections in 10 random x 20 power fields. The staining intensity was graded as: 0 , no staining; 1 , weak; 2 , moderate; 3 , strong. The percentage of positive cells was scored as: $1,<25 \% ; 2,26-50 \% ; 3,51-75 \% ; 4,>76 \%$. These 2 scores were added together. Based on the sum of the scores, each tissue sample was categorized into 4 groups: $0, \leq 5 \%$ cells were stained; 1-3, weak expression; 4-5, moderate expression; and 6-7, strong expression. Finally, we compared statistically the numbers of cells with low-to-weak expression with those with moderate-to-strong expression. 
Table I. Clinicopathological features of HCC patients by p57 and RhoA expression.

\begin{tabular}{|c|c|c|c|c|c|c|c|}
\hline \multirow[b]{2}{*}{ Characteristic } & \multirow[b]{2}{*}{$\mathrm{n}(\%)$} & \multicolumn{2}{|c|}{ p57 } & \multirow[b]{2}{*}{ P-value } & \multicolumn{2}{|c|}{ RhoA } & \multirow[b]{2}{*}{ P-value } \\
\hline & & Positive, $\mathrm{n}$ & Negative, $\mathrm{n}$ & & Positive, $\mathrm{n}$ & Negative, $\mathrm{n}$ & \\
\hline \multicolumn{8}{|l|}{ Age (years) } \\
\hline$<45$ & $30(37.5)$ & 11 & 19 & 0.809 & 19 & 11 & 0.637 \\
\hline$\geq 45$ & $50(63.5)$ & 17 & 33 & & 29 & 21 & \\
\hline \multicolumn{8}{|l|}{ Gender } \\
\hline Male & $56(70.0)$ & 20 & 36 & 0.838 & 36 & 20 & 0.232 \\
\hline Female & $24(30.0)$ & 8 & 16 & & 12 & 12 & \\
\hline \multicolumn{8}{|l|}{ Histopathology } \\
\hline Massive & $29(36.3)$ & 9 & 20 & 0.575 & 15 & 14 & 0.255 \\
\hline Nodular & $51(63.7)$ & 19 & 32 & & 33 & 18 & \\
\hline \multicolumn{8}{|l|}{$\mathrm{HBsAg}$} \\
\hline Positive & $72(90.0)$ & 23 & 49 & 0.086 & 45 & 27 & 0.171 \\
\hline Negative & $8(10.0)$ & 5 & 3 & & 3 & 5 & \\
\hline \multicolumn{8}{|l|}{ AFP (ng/ml) } \\
\hline$<400$ & $32(40.0)$ & 7 & 25 & $0.044^{\mathrm{a}}$ & 21 & 11 & 0.402 \\
\hline$\geq 400$ & $48(60.0)$ & 21 & 27 & & 27 & 21 & \\
\hline \multicolumn{8}{|l|}{ Tumor size $(\mathrm{cm})$} \\
\hline$<5$ & $28(35.0)$ & 4 & 24 & $0.004^{\mathrm{b}}$ & 20 & 8 & 0.126 \\
\hline$\geq 5$ & $52(65.0)$ & 24 & 28 & & 28 & 24 & \\
\hline \multicolumn{8}{|c|}{ Histological grade } \\
\hline Well/moderate & $34(42.5)$ & 7 & 27 & $0.020^{\mathrm{a}}$ & 16 & 18 & $0.042^{\mathrm{a}}$ \\
\hline Poor & $46(57.5)$ & 21 & 25 & & 32 & 14 & \\
\hline \multicolumn{8}{|l|}{ TNM stage } \\
\hline $\mathrm{I}+\mathrm{II}$ & $27(33.8)$ & 5 & 22 & $0.027^{\mathrm{a}}$ & 20 & 7 & 0.067 \\
\hline $\mathrm{III}+\mathrm{IV}$ & $53(66.2)$ & 23 & 30 & & 28 & 25 & \\
\hline \multicolumn{8}{|l|}{ Capsule invasion } \\
\hline Positive & $52(65.0)$ & 23 & 29 & $0.018^{\mathrm{a}}$ & 36 & 16 & $0.022^{\mathrm{a}}$ \\
\hline Negative & $28(35.0)$ & 5 & 23 & & 12 & 16 & \\
\hline \multicolumn{8}{|c|}{ Tumor thrombosis } \\
\hline Positive & $44(55.0)$ & 21 & 23 & $0.008^{\mathrm{b}}$ & 33 & 11 & $0.002^{\mathrm{b}}$ \\
\hline Negative & $36(45.0)$ & 7 & 29 & & 15 & 21 & \\
\hline
\end{tabular}

${ }^{\mathrm{a}} \mathrm{P}<0.05 ;{ }^{\text {b }}<0.01 ; \mathrm{HCC}$, hepatocellular carcinoma; RhoA, Ras homology A.

Statistical analysis. Data were analyzed using the Student's t-test and the Chi-square $\left(\chi^{2}\right)$ test. Spearman $r$ test was used to analyze the correlation between p57 and RhoA expression. Survival curves were plotted using the Kaplan-Meier method. The log-rank test for trend was used for the ordinal datum of univariate analysis, and a Cox proportional hazards regression model was used for the multivariate analysis of survival duration. Statistical Package for Social Science (SPSS) version 16.0 (Chicago, IL, USA) was used to generate the P-value for each test, and all reported $\mathrm{P}$-values were two-sided. A P-value $<0.05$ was considered to indicate a statistically significant result.

\section{Results}

Expression of p57 $m R N A$ and protein. We assessed levels of p57 mRNA using qRT-PCR in the 80 pairs of HCC and adjacent non-cancerous tissues. The level of p57 mRNA was significantly lower in the HCC tissues than the level in the distant non-cancerous tissues $(0.1670 \pm 0.1014$ compared with $0.8214 \pm 0.1926, \mathrm{P}<0.01$, Fig. 1A). Moreover, we analyzed the expression of p57 protein using immunohistochemistry and found that compared to the p57 expression in paired normal tissues $(50 / 80,62.5 \%)$, expression of p57 was absent in 52 of the $80 \mathrm{HCC}$ tissues $(65.0 \%)$. The immunohistochemical data confirmed the qRT-PCR data and indicated that p57 was significantly reduced in HCC tissues when compared with that of the distant non-cancerous tissues $\left(\chi^{2}=12.108, \mathrm{P}=0.001\right.$, Fig. 2).

We also investigated the association between p57 expression and clinicopathological data of the HCC patients. Our data showed that loss of expression of p57 was associated with HCC with higher $\alpha$-fetoprotein (AFP) levels (>400 ng/ml; $\mathrm{P}=0.044)$, 

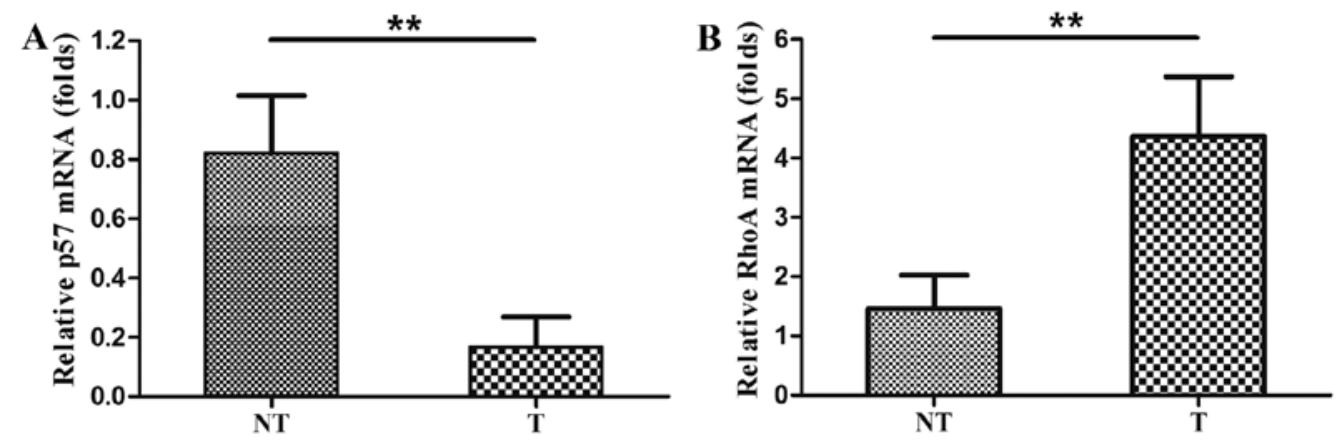

Figure 1. qRT-PCR detection of p57 and RhoA mRNA levels in HCC and normal tissue specimens. (A) The relative expression of p57 mRNA in $80 \mathrm{HCC}$ tissues compared with matched distant non-tumor tissues. (B) The relative expression of RhoA mRNA in 80 HCC tissues compared with the distant non-tumor tissues $\left({ }^{* *} \mathrm{P}<0.01\right)$. NT, distant non-tumor tissues; T, tumor tissues; RhoA, Ras homology A; HCC, hepatocellular carcinoma.
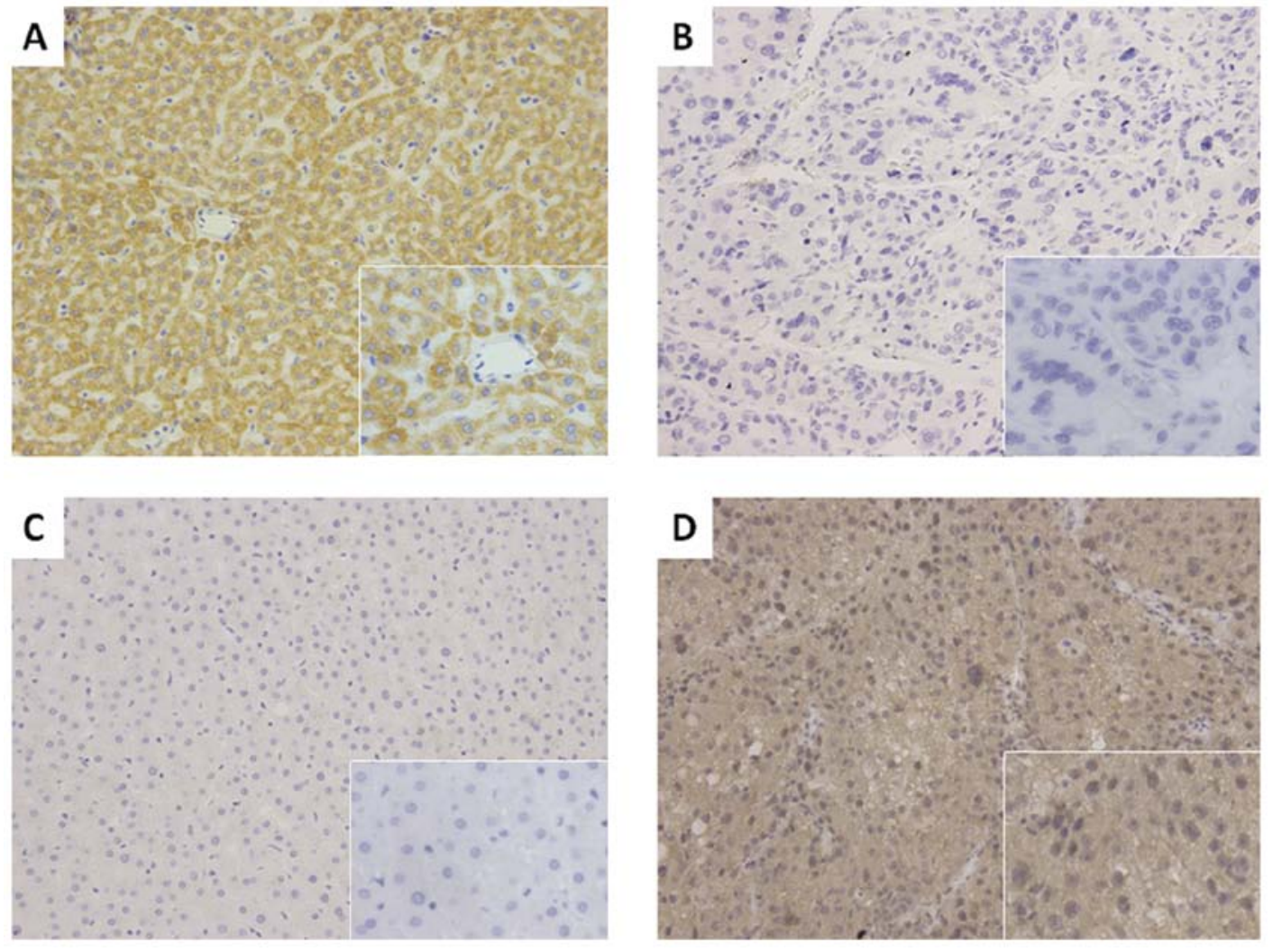

Figure 2. Immunohistochemical detection of p57 and RhoA expression in HCC and corresponding distant non-tumor tissues (x200). (A) Expression of p57 in distant non-tumor tissues (50/80, 62.5\%). (B) Loss of expression of p57 in HCC tissues (52/80, 65.0\%). (C) No expression of RhoA in distant non-tumor tissues (46/80, 57.5\%). (D) Overexpression of RhoA in HCC tissues (48/80, 60.0\%). The insets show images captured at x400 magnification. RhoA, Ras homology A; HCC, hepatocellular carcinoma.

larger tumor size $(>5 \mathrm{~cm}, \mathrm{P}=0.004)$, poor tumor differentiation $(\mathrm{P}=0.020)$, advanced TNM stage $(\mathrm{P}=0.027)$, presence of capsule invasion $(\mathrm{P}=0.018)$ and tumor thrombosis $(\mathrm{P}=0.008$; Table I).

Expression of RhoA $m R N A$ and protein. We analyzed RhoA expression in the $80 \mathrm{HCC}$ tissues and the corresponding noncancerous tissues. We found that the average level of RhoA mRNA expression in HCC tissues was significantly higher than that of the distant non-cancerous tissues $(4.3659 \pm 1.0056$ compared with $1.4571 \pm 0.5641, \mathrm{P}<0.01$, Fig. 1B). Similarly, expression of RhoA protein was also significantly higher in
HCC tissues $(60.0 \%, 48 / 80)$ when compared with the paired normal tissues $\left(42.5 \%, 34 / 80 ; \chi^{2}=4.903, \mathrm{P}=0.027\right.$, Fig. 2$)$.

Expression of RhoA protein was found to be significantly associated with poor tumor differentiation $(\mathrm{P}=0.042)$, the presence of capsule invasion $(\mathrm{P}=0.022)$, and tumor thrombosis $(\mathrm{P}=0.002$; Table I).

Association between 557 and RhoA expression in HCC tissue specimens. As discussed in the Introduction, expression of p57 protein inhibits tumor cell migration and invasion, and the latter may be associated with RhoA activation; thus, we investigated the association between p57 and RhoA levels in 

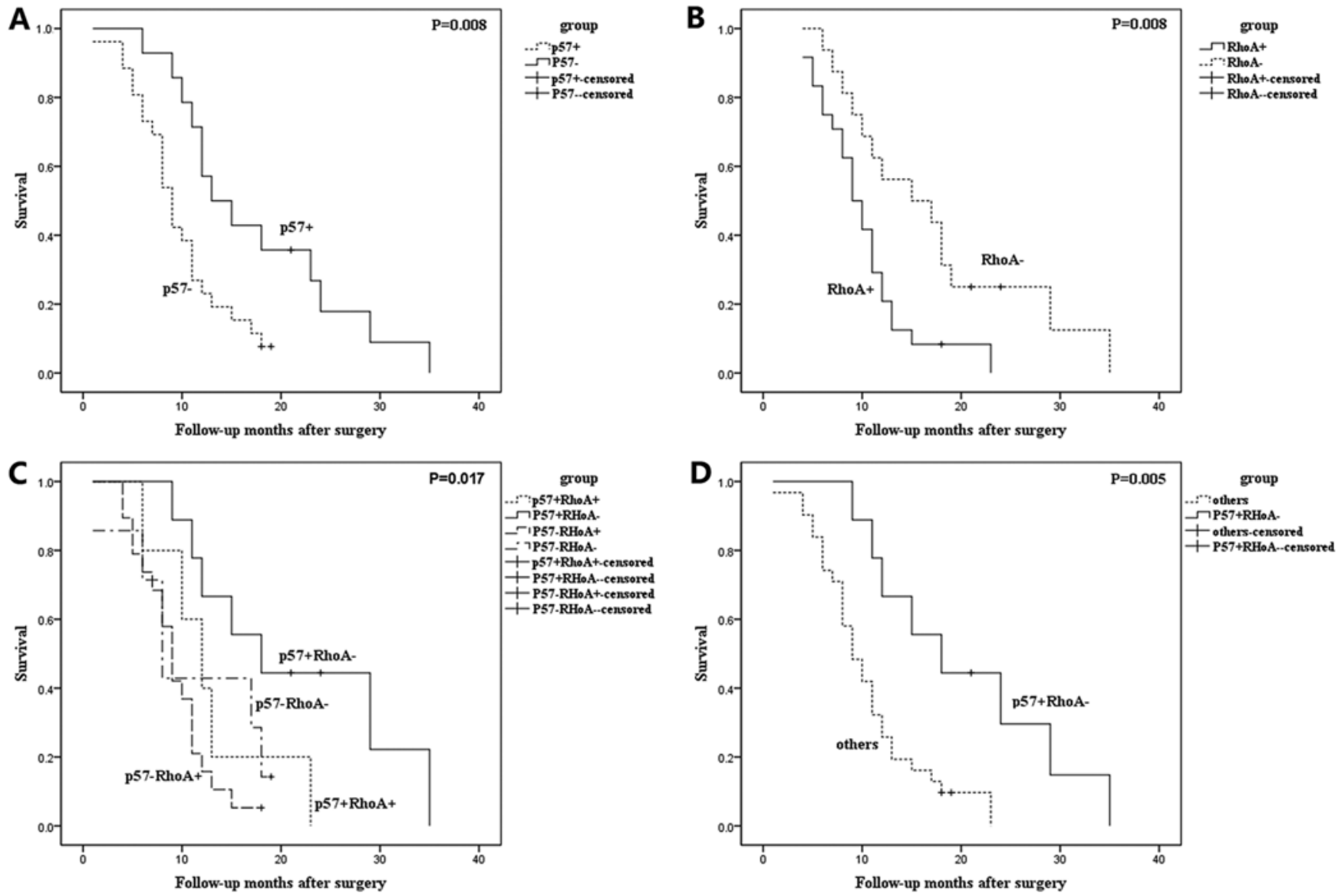

Figure 3. Kaplan-Meier survival curve analyses of the association between $\mathrm{p} 57$ and RhoA expression and overall survival of HCC patients using the log rank

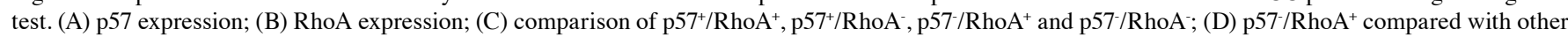
expression combinations. RhoA, Ras homology A; HCC, hepatocellular carcinoma.

Table II. Association between p57 and RhoA expression in normal and HCC tissue specimens.

\begin{tabular}{lcccc}
\hline & \multicolumn{2}{c}{$\mathrm{p} 57$} & & \\
\cline { 2 - 4 } RhoA & $\begin{array}{c}\text { Positive } \\
\mathrm{n}(\%)\end{array}$ & $\begin{array}{c}\text { Negative } \\
\mathrm{n}(\%)\end{array}$ & $\mathrm{r}$ & P-value \\
\hline $\begin{array}{l}\text { Tumor tissue } \\
\text { Positive }\end{array}$ & $10(12.5)$ & $38(47.5)$ & -0.364 & 0.001 \\
$\quad$ Negative & $18(22.5)$ & $14(17.5)$ & & \\
Normal tissue & & & & \\
$\quad \begin{array}{l}\text { Positive } \\
\text { Negative }\end{array}$ & $17(21.2)$ & $17(21.2)$ & -0.270 & 0.016 \\
\hline
\end{tabular}

RhoA, Ras homology A; HCC, hepatocellular carcinoma.

the HCC and matched normal tissues. For analysis, we divided the $80 \mathrm{HCC}$ specimens into groups according to expression:

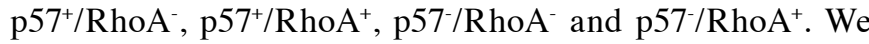
found that there was a strong inverse relationship between p57 and RhoA expression in the HCC tissues. Notably, co-expression (p57-lower and RhoA-higher) was detected in 38 of the 80 tumors $(47.5 \%)$, which was statistically significant $(r=-0.364, P=0.001$; Table II). These results indicate that loss of p57 expression may contribute to RhoA overexpression in $\mathrm{HCC}$ tissues. In addition, we found that there also was an inverse relationship between $\mathrm{p} 57$ and RhoA expression in distant normal tissues ( $\mathrm{r}=-0.270, \mathrm{P}=0.016$; Table II).

Association between $p 57$ and RhoA expression and overall survival of HCC patients. All of the 80 patients were followed up for survival until December 2012, and their survival data were stratified according to p57 and RhoA expression. Of the 80 patients, 77 died during the follow-up period and the 3 -year survival rate was $3.75 \%$. Survival time ranged from $<4$ months to $>33$ months, with a median survival time of 11.0 months.

The median survival time of HCC patients with $\mathrm{p} 57^{+}$and p57 was 13.0 and 9.0 months, respectively, whereas the median survival time of $\mathrm{HCC}$ patients with $\mathrm{RhoA}^{+}$and $\mathrm{RhoA}^{-}$was 9.0 and 15.0 months, respectively. This supports the usefulness of $\mathrm{p} 57$ and RhoA proteins as prognostic markers for $\mathrm{HCC}$ patients $(\mathrm{P}<0.05$, Fig. $3 \mathrm{~A}$ and $\mathrm{B})$.

We then analyzed the association between the expression groups ( $557^{+} / \mathrm{RhoA}^{-}, \mathrm{p}^{2} 7^{+} / \mathrm{RhoA}^{+}, \mathrm{p} 57^{-} / \mathrm{RhoA}^{-}$and $\mathrm{p} 57-/$ $\mathrm{RhoA}^{+}$) with the survival of the HCC patients. The median

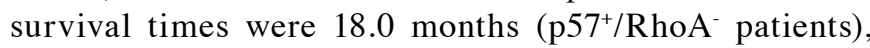
12.0 months (p57/ $\left.\mathrm{RhoA}^{+}\right), 9.0$ months (p57/RhoA) and 8.0 months $\left(\mathrm{p} 57^{-} / \mathrm{RhoA}^{+}\right)$. These differences were statistically 
Table III. Univariate analysis of survival data.

\begin{tabular}{ll}
\hline Clinicopathological characteristics & P-value \\
\hline Age, $<45$ vs. $\geq 45$ years & 0.382 \\
Gender, male vs. female & 0.331 \\
Histopathology, massive vs. nodular & 0.446 \\
AFP, <400 vs. $\geq 400 \mathrm{ng} / \mathrm{ml}$ & $0.034^{\mathrm{a}}$ \\
Hepatitis B virus infection, positive vs. negative & 0.660 \\
Tumor size, $<5$ vs. $\geq 5 \mathrm{~cm}$ & $0.010^{\mathrm{a}}$ \\
Histological grade, well/moderate vs. poor & $0.031^{\mathrm{a}}$ \\
TNM stage, I + II vs. III + IV & $0.020^{\mathrm{a}}$ \\
Capsule invasion, positive vs. negative & $0.025^{\mathrm{a}}$ \\
Tumor thrombosis, positive vs. negative & $0.005^{\mathrm{b}}$ \\
p57, positive vs. negative & $0.008^{\mathrm{b}}$ \\
RhoA, positive vs. negative & $0.008^{\mathrm{b}}$ \\
Co-expression of p57 and RhoA, p57 $/ \mathrm{RhoA}^{+}$ & $0.007^{\mathrm{b}}$ \\
vs. others &
\end{tabular}

${ }^{\mathrm{a}} \mathrm{P}<0.05 ;{ }^{\text {b }} \mathrm{P}<0.01$.

significant ( $\mathrm{P}=0.017$, Fig. 3C). Moreover, HCC patients with RhoA expression but with loss of p57 expression (p57//RhoA $\left.{ }^{+}\right)$ tended to have poorer outcomes than those with other expression combinations $(\mathrm{P}=0.007$, Fig. 3D).

Relatedness of survival with clinicopathological factors and molecular markers. We grouped significant factors for the analysis of prognostic factors (Table III). The log-rank test data revealed that the levels of AFP, tumor size, TNM stage, histological grade, capsule invasion, tumor thrombosis, p57, RhoA, and co-expression of p57 and RhoA were all significant prognostic indicators for overall survival of HCC patients $(\mathrm{P}<0.05$, Table III). According to the results of the multivariate analysis of these factors, the predictive ability of tumor size, TNM stage, p57, RhoA, and p57- RhoA $^{+}$expression was confirmed $(\mathrm{P}<0.05$, Table IV). However, there were no significant associations between prognosis and the other clinicopathological features.

\section{Discussion}

In the present study, we analyzed the expression of p57 and RhoA mRNA and p57 and RhoA protein for associations with clinicopathological data and survival. We found that the combination of the loss of expression of p57 mRNA and protein and overexpression of RhoA mRNA and protein in HCC tissue specimens was significantly more apparent than in distant normal tissues. The loss of expression of p57 associated with HCC was also correlated with higher AFP levels, larger tumor size, and poor differentiation of the tumor, advanced TNM stages, tumor capsule invasion and tumor thrombosis. However, among the clinicopathological features we analyzed, expression of RhoA protein was positively associated only with poor tumor differentiation, tumor capsule invasion and tumor thrombosis. Furthermore, loss of p57 expression was associated with RhoA overexpression in HCC tissues, and the $\mathrm{p} 57 / \mathrm{RhoA}^{+}$protein combination contributed to the poor survival of HCC patients. Multivariate analysis verified that tumor size, TNM stage, p57, RhoA, and loss of p57 with RhoA all were risk factors for predicting the poor survival of HCC patients. This study indicates that detection of p57 and RhoA, taken together, will predict HCC overall survival.

Tumor cell proliferation, invasion, and metastasis are defining characteristics of malignant phenotypes in human cancers. Although much is known regarding the molecular alterations associated with cancer invasion and metastasis, more research is needed to fully understand the underlying molecular mechanisms. Recent studies have shown that $\mathrm{p} 57$ protein has many functions in cancer cells, including regulation of cell cycle distribution, apoptosis, cell migration and cytoskeletal dynamics. The latter contributes not only to tumor cell proliferation but also invasion and metastasis $(14,15)$. We found in the present study that loss of expression of p57 mRNA and protein was associated with advanced HCC stage and poor prognosis. These results imply that p57 is a tumor-suppressor gene.

Although the process by which $\mathrm{p} 57$ protein functions to suppress HCC development or progression is still unknown,

Table IV. Multivariate analysis of overall survival in the 80 HCC cases.

\begin{tabular}{|c|c|c|c|}
\hline Clinicopathological characteristics & P-value & $\operatorname{Exp}(B)$ & $95 \% \mathrm{CI}$ \\
\hline AFP, $<400 \mathrm{vs} . \geq 400 \mathrm{ng} / \mathrm{ml}$ & 0.492 & 3.335 & $0.107-103.590$ \\
\hline Tumor size, $\geq 5$ vs. $<5 \mathrm{~cm}$ & $0.011^{\mathrm{a}}$ & 2.251 & $1.102-4.216$ \\
\hline Histological grade, well/moderate vs. poor & 0.447 & 3.617 & $0.132-99.431$ \\
\hline TNM stage, I + II vs. III + IV & $0.033^{\mathrm{a}}$ & 4.274 & $1.127-16.212$ \\
\hline Capsule invasion, positive vs. negative & 0.780 & 0.671 & $0.041-11.024$ \\
\hline Tumor thrombosis, positive vs. negative & 0.101 & 0.105 & $0.007-1.551$ \\
\hline p57, high vs. low expression & $0.032^{\mathrm{a}}$ & 0.369 & $0.101-0.853$ \\
\hline RhoA, high vs. low expression & $0.020^{\mathrm{a}}$ & 1.694 & $1.086-2.640$ \\
\hline Co-expression of p57 and RhoA, p57-/RhoA ${ }^{+}$vs. others & $0.010^{\mathrm{a}}$ & 6.162 & $1.551-24.485$ \\
\hline
\end{tabular}

${ }^{\mathrm{a}} \mathrm{P}<0.05 ; \mathrm{CI}$, confidence interval. 
we did find that loss of expression of p57 protein was associated with upregulation of RhoA protein, i.e., RhoA protein was elevated in 48 cases of HCC tissue samples, while p57 was downregulated in 52 of 80 cases. This suggests that the combination of loss of p57 expression and elevated RhoA has a synergistic effect on HCC tumorigenesis and progression.

RhoA family proteins are known for their roles in the regulation of actin-stress fiber formation, focal-adhesion assembly, as well as actin-myosin contractility (19). Thus, activation of the Rho-ROCK-LIMK-cofilin signaling pathway promotes cell mobility and migration. The latter are characterized by less or poor cell differentiation, and our current data showed that overexpression of RhoA protein was associated with poor tumor differentiation, tumor capsule invasion, and tumor thrombosis in HCC lesions, all of which are phenotypes of tumor invasion and metastasis.

Previous studies have shown that expression and activation of RhoA protein are correlated with tumor progression (23) and a poor prognosis in human breast cancer (24). However, different mechanisms may be involved in regulating the overexpression and function of RhoA protein. For example, it has been proven that $\mathrm{p} 27$ and $\mathrm{p} 21$ proteins may have a role in modulating cytoskeletal dynamics by binding to RhoA or ROCK (25-27). Notably, RhoA can also negatively regulate the levels of p27 and p21 proteins (28-33). Thus, there may be a negative-feedback loop between cyclin-dependent kinase inhibitors (CKIs) and Rho family proteins. Our previous data showed that p57 protein inhibited the proliferation and invasion of HCC cells through inhibition of LIM domain kinase 1 (LIMK1)/phospho-cofilin signaling (3). LIMK1 principally acts downstream of Rho GTPases. However, the precise mechanism by which p57 inhibits RhoA signaling in HCC cells warrants further investigation.

In previous clinical studies, altered expression of p57 or RhoA protein was associated with biologically aggressive tumor phenotypes and with poor prognosis of cancer patients (34-36). The present study supports these published data. However, we further showed that tumor size, TNM stage, p57, RhoA, and loss of p57 combined with RhoA expression all were independent factors for survival of HCC patients. These data suggest that altered expression of p57 and RhoA may be associated with advanced aggressive tumor phenotypes, and both p57 and RhoA may be independent predictors of the survival of HCC patients.

\section{Acknowledgements}

This study was supported in part by a grant from the National Natural Science Foundation of China (nos. 81172361 and 81201923). The authors thank Professor Chen Huang of Xi'an Jiaotong University (Xi'an, China) for providing the experimental platform and expert opinions, and Mr. Song Ren for his technical assistance.

\section{References}

1. Jemal A, Bray F, Center MM, Ferlay J, Ward E and Forman D Global cancer statistics. CA Cancer J Clin 61: 69-90, 2011.

2. Pateras IS, Apostolopoulou K, Niforou K, Kotsinas A and Gorgoulis VG: p57 ${ }^{\mathrm{KIP} 2}$ : 'Kip'ing the cell under control. Mol Cancer Res 7: 1902-1919, 2009.
3. Guo H, Lv Y, Tian T, Hu TH, Wang WJ, Sui X, Jiang L, Ruan ZP and Nan KJ: Downregulation of p57 accelerates the growth and invasion of hepatocellular carcinoma. Carcinogenesis 32: 1897-1904, 2011

4. Lee MH, Reynisdóttir I and Massagué J: Cloning of p57 $7^{\mathrm{KI} 2}$, a cyclin-dependent kinase inhibitor with unique domain structure and tissue distribution. Genes Dev 9: 639-649, 1995.

5. Malik K and Brown KW: Epigenetic gene deregulation in cancer. Br J Cancer 83: 1583-1588, 2000.

6. Lee MH and Yang HY: Negative regulators of cyclin-dependent kinases and their roles in cancers. Cell Mol Life Sci 58: 1907-1922, 2001.

7. Lee SH, Lee JK, Jin SM, Lee KC, Sohn JH, Chae SW and Kim DH: Expression of cell-cycle regulators (cyclin D1, cyclin E, p $27^{\mathrm{kipl}}, \mathrm{p} 57^{\mathrm{kip2}}$ ) in papillary thyroid carcinoma. Otolaryngol Head Neck Surg 142: 332-337, 2010.

8. Larson PS, Schlechter BL, King CL, Yang Q, Glass CN, Mack C, Pistey R, de Las Morenas A and Rosenberg CL: $C D K N 1 C / \mathrm{p} 57^{\mathrm{kip} 2}$ is a candidate tumor suppressor gene in human breast cancer. BMC Cancer 8: 68, 2008.

9. Li JQ, Wu F, Usuki H, Kubo A, Masaki T, Fujita J, Bandoh S, Saoo K, Takeuchi H, Kuriyama S, Ishida T and Imaida K: Loss of p57 ${ }^{\mathrm{KIP} 2}$ is associated with colorectal carcinogenesis. Int J Oncol 23: 1537-1543, 2003.

10. Jin RJ, Lho Y, Wang Y, Ao M, Revelo MP, Hayward SW, Wills ML, Logan SK, Zhang P and Matusik RJ: Down-regulation of $\mathrm{p} 57^{\mathrm{Kip} 2}$ induces prostate cancer in the mouse. Cancer Res 68 : 3601-3608, 2008

11. Schwarze SR, Shi Y, Fu VX, Watson PA and Jarrard DF: Role of cyclin-dependent kinase inhibitors in the growth arrest at senescence in human prostate epithelial and uroepithelial cells. Oncogene 20: 8184-8192, 2001.

12. Yan Y, Frisén J, Lee MH, Massagué J and Barbacid M: Ablation of the CDK inhibitor p57Kip2 results in increased apoptosis and delayed differentiation during mouse development. Genes Dev 11: 973-983, 1997.

13. Zhang P,Liégeois NJ, Wong C, Finegold M, Hou H, Thompson JC, Silverman A, Harper JW, DePinho RA and Elledge SJ: Altered cell differentiation and proliferation in mice lacking p57 ${ }^{\mathrm{KIP} 2}$ indicates a role in Beckwith-Wiedemann syndrome. Nature 387: 151-158, 1997.

14. Besson A, Assoian RK and Roberts JM: Regulation of the cytoskeleton: an oncogenic function for CDK inhibitors? Nat Rev Cancer 4: 948-955, 2004

15. Guo H, Tian T, Nan K and Wang W: p57: A multifunctional protein in cancer (Review). Int J Oncol 36: 1321-1329, 2010.

16. Ridley AJ, Schwartz MA, Burridge K, Firtel RA, Ginsberg MH, Borisy G, Parsons JT and Horwitz AR: Cell migration: integrating signals from front to back. Science 302: 1704-1709, 2003.

17. Aspenström P, Fransson A and Saras J: Rho GTPases have diverse effects on the organization of the actin filament system. Biochem J 377: 327-337, 2004.

18. Ridley AJ and Hall A: The small GTP-binding protein rho regulates the assembly of focal adhesions and actin stress fibers in response to growth factors. Cell 70: 389-399, 1992.

19. Etienne-Manneville S and Hall A: Rho GTPases in cell biology. Nature 420: 629-635, 2002.

20. Gómez del Pulgar T, Benitah SA, Valerón PF, Espina C and Lacal JC: Rho GTPase expression in tumourigenesis: evidence for a significant link. Bioessays 27: 602-613, 2005.

21. Pan Y, Bi F, Liu N, Xue Y, Yao X, Zheng Y and Fan D: Expression of seven main Rho family members in gastric carcinoma. Biochem Biophys Res Commun 315: 686-691, 2004.

22. Wong CC, Wong CM, Au SL and Ng IO: RhoGTPases and Rho-effectors in hepatocellular carcinoma metastasis: ROCK N'Rho move it. Liver Int 30: 642-656, 2010.

23. Pillé JY, Denoyelle C, Varet J, Bertrand JR, Soria J, Opolon P, Lu H, Pritchard LL, Vannier JP, Malvy C, Soria C and Li H: Anti-RhoA and anti-RhoC siRNAs inhibit the proliferation and invasiveness of MDA-MB-231 breast cancer cells in vitro and in vivo. Mol Ther 11: 267-274, 2005.

24. Fritz G, Just I and Kaina B: Rho GTPases are over-expressed in human tumors. Int J Cancer 81: 682-687, 1999.

25. Lee $\mathrm{S}$ and Helfman DM: Cytoplasmic p $21^{\text {Cipl }}$ is involved in Ras-induced inhibition of the ROCK/LIMK/cofilin pathway. J Biol Chem 279: 1885-1891, 2004.

26. Wang XQ, Lui EL, Cai Q, Ching WY, Liu KS, Poon RT and Fan ST: p2 $7^{\text {Kipl }}$ promotes migration of metastatic hepatocellular carcinoma cells. Tumour Biol 29: 217-223, 2008. 
27. Larrea MD, Hong F, Wander SA, da Silva TG, Helfman D Lannigan D, Smith JA and Slingerland JM: RSK1 drives p27 $7^{\mathrm{Kip}}$ phosphorylation at T198 to promote RhoA inhibition and increase cell motility. Proc Natl Acad Sci USA 106: 9268-9273, 2009.

28. Croft DR and Olson MF: The Rho GTPase effector ROCK regulates cyclin A, cyclin D1, and $\mathrm{p} 27^{\mathrm{Kip} 1}$ levels by distinct mechanisms. Mol Cell Biol 26: 4612-4627, 2006.

29. Lai JM, Wu S, Huang DY and Chang ZF: Cytosolic retention of phosphorylated extracellular signal-regulated kinase and a Rho-associated kinase-mediated signal impair expression of $\mathrm{p} 21^{\text {Cip1/Waf1 }}$ in phorbol 12-myristate-13- acetate-induced apoptotic cells. Mol Cell Biol 22: 7581-7592, 2002.

30. Mammoto A, Huang S, Moore K, Oh P and Ingber DE: Role of RhoA, mDia, and ROCK in cell shape-dependent control of the Skp2-p27 $7^{\text {kipl }}$ pathway and the $\mathrm{G}_{1} / \mathrm{S}$ transition. J Biol Chem 279: 26323-26330, 2004.

31. Sahai E, Ishizaki T, Narumiya $S$ and Treisman R: Transformation mediated by RhoA requires activity of ROCK kinases. Curr Biol 9: 136-145, 1999.
32. Sahai E, Olson MF and Marshall CJ: Cross-talk between Ras and Rho signalling pathways in transformation favours proliferation and increased motility. EMBO J 20: 755-766, 2001.

33. Zhang S, Tang Q, Xu F, Xue Y, Zhen Z, Deng Y, Liu M, Chen J, Liu S, Qiu M, Liao Z, Li Z, Luo D, Shi F, Zheng Y and Bi F: RhoA regulates $\mathrm{G}_{1}-\mathrm{S}$ progression of gastric cancer cells by modulation of multiple INK4 family tumor suppressors. Mol Cancer Res 7: 570-580, 2009.

34. Fan GK, Xu F, Yang B and Fujieda S: p57 $7^{\mathrm{kip} 2}$ expression is related to carcinogenesis and tumor progression in laryngeal tissues. Acta Otolaryngol 126: 301-305, 2006.

35. Biaoxue R, Xiguang C, Hua L, Hui M, Shuanying Y, Wei Z, Wenli S and Jie D: Decreased expression of decorin and p57(KIP2) correlates with poor survival and lymphatic metastasis in lung cancer patients. Int J Biol Markers 26: 9-21, 2011.

36. Ma L, Liu YP, Geng CZ, Wang XL, Wang YJ and Zhang XH: Overexpression of RhoA is associated with progression in invasive breast duct carcinoma. Breast J 16: 105-107, 2010. 